\title{
LAYANAN INFORMASI PEREKRUTAN DAN PENYALUR TENAGA KERJA BERBASIS SHORT MESSAGE SERVICE
}

\author{
Sarwindah \\ Indah_syifa@atmaluhur.ac.id \\ STMIK Atma Luhur, Sistem Informasi Pangkalpinang
}

\begin{abstract}
Abstrak
Dengan meningkatnya kebutuhan masyarakat akan informasi dan hiburan, maka penggunaan media SMS sebagai alat permintaan dan penyebaran suatu layanan informasi sangat efisien dan inovatif. Untuk keperluan ini, kalangan bisnis dan perkantoran yang ingin menyediakan layanan informasi berbasis SMS membutuhkan aplikasi-aplikasi yang dapat mendukung pelayanan ini.SMS Penyaluran Tenaga Kerja adalah salah satu layanan untuk merekrut tenaga kerja malalui SMS. Selain itu juga mempermudah dalam mendapatkan jadwal interview bagi para kandidat atau pencari kerja. Aplikasi ini berjalan setelah sistem menerima SMS yang masuk melalui handphone sebagai servermya. Setelah diproses oleh komputer hasilnya akan dikirim kembali kepada klien ataupun kandidat yang meminta melalui handphone. Selain itu ada sistem broadcast yang bersifat pengumuman yang memberitahukan kepada klien ataupun kandidat.Pemrograman Java ini multi platform yaitu dapat digunakan di berbagai Operasi Sistem maupun Windows.Dengan dikembangkannya aplikasi ini, diharapkan dapat membantu para klien ataupun para kandidat untuk mendapatkan informasi yang diinginkan lebih cepat.
\end{abstract}

Kata kunci: Informasi, Layanan dan Short Message Service

\begin{abstract}
With the increasing public demand for information and entertainment, the use of SMS media as a means of requesting and distributing information services is very efficient and innovative. For this purpose, businesses and offices that want to provide SMS-based information services require applications that can support this service. MS Workforce Distribution is one of the services to recruit workers through SMS. Besides that, it is also easier to get interview schedules for candidates or job seekers. This application runs after the system receives SMS that enters via mobile as the server. After being processed by a computer, the results will be sent back to the client or candidate who requested via mobile. In addition, there are broadcast systems that are announcements that inform clients or candidates. Java programming is multi-platform which can be used in a variety of System Operations and Windows. With the development of this application, it is expected to help clients or candidates to get the desired information faster.
\end{abstract}

Keywords: Information, Services and Short Message Service.

\section{Pendahuluan}

Teknologi komunikasi berkembang sangat pesat seiring dengan semakin banyaknya permintaan masyarakat akan teknologi tersebut. Salah satu teknologi yang berkembang saat ini adalah Global System for Mobile Communication (GSM) atau yang lebih dikenal dengan telepon selular telepon digital. Seiring perkembangannya sekarang ini teknologi telepon bergerak tidak hanya digunakan untuk berkomunikasi suara dengan lawan bicara, tetapi juga dapat digunakan untuk saling berkirim pesan dengan orang lain melalui teks atau yang lebih populer disebut dengan SMS (Short Message Service). Media SMS sekarang ini sedang marak digunakan oleh para pengguna telepon bergerak dikarenakan biaya yang dikeluarkan lebih murah. Maraknya penggunaan SMS sekarang ini, membuat berkembangnya layanan-layanan berbasis SMS, seperti informasi cuaca, jadwal film di bioskop, humor, gosip sampai informasi kegiatan para selebritis dan layanan yang cukup kompleks seperti SMS banking. Cara pengoperasiannya pun cukup mudah, misalnya untuk mengetahui kegiatan para selebritis tinggal mengetikkan nama selebritis yang diidolakan, kemudian mengirimkannya ke nomor tertentu, maka tidak berselang lama SMS yang berisi informasi yang diminta akan diperoleh. Begitu juga dengan penyaluran tenaga kerja di PT. HITSS, untuk melayani para klien dan para kandidat PT. HITSS ingin memberikan pelayanan yang terbaik, sehingga dibuatlah aplikasi ini untuk melayani para klien dan kandidat dalam hal perekrutan dan jadwal interview. Mengingat sibuknya operator di PT. HITSS yang menjawab telepon dari para klien yang ingin merekrut tenaga kerja dan para kandidat yang ingin mengetahui jadwal interview. Hal itu membuat sering kali jika menelepon ke PT. HITSS selalu sibuk, untuk memudahkan para klien dan 
para kandidat untuk mengetahui informasi dari PT. HITSS maka dibutuhkan suatu sistem yang mempermudah kerja dari operator. Dengan sistem ini para klien dan para kandidat dapat mendapatkan informasi dengan cara yang mudah, cepat dan dapat dilakukan di mana saja dan kapan saja. Dengan adanya permasalahan diatas, maka dikembangkan suatu aplikasi penyaluran tenaga kerja berbasis SMS. Adapun tujuan penulisan ini adalah sebagai berikut, Mempermudah para klien dan kandidat untuk mendapatkan informasi juga menghemat biaya dan waktu yang harus dikeluarkan.

\section{Metode}

\subsection{Konsep Sistem}

Istilah sistem bukanlah hal yang asing bagi kebanyakan orang. sistem adalah : "Sekumpulan elemen yang saling terkait atau terpadu yang dimaksudkan untuk mencapai suatu tujuan". [1]

Definisi lain informasi adalah data yang telah diproses atau disusun kedalam suatu format lebih berarti untuk seseorang, informasi dibentuk dari kombinasi data yang dengan penuh harapan dapat mempunyai arti bagi penerimanya.[2]

\subsection{Konsep Informasi}

informasi adalah data yang telah diproses atau disusun kedalam suatu format lebih berarti untuk seseorang, informasi dibentuk dari kombinasi data yang dengan penuh harapan dapat mempunyai arti bagi penerimanya. [3]

Sehingga dalam kaitannya sistem dan informasi mempunyai hubungan yang sangat erat. Dalam sistem informasi, terdapat inti dan tujuan, yaitu menghasilkan informasi itu sendiri. Sesederhana apapun sistem informasi yang dikembangkan, jika bisa menghasilkan informasi yang diharapkan, maka pengembangannya dikatakan berhasil begitu pula sebaliknya jika informasi tidak dapat dihasilkan sesuai yang diharapkan. [3]

\subsection{SMS (Short Message Service)}

Short message service (SMS) merupakan salah satu layanan pesan teks yang dikembangkan dan distandarisasi oleh suatu badan yang bernama ETSI (European Telecomunication Standards Institute). SMS dapat dikirimkan ke perangkat stasiun Seluler Digital lainnya hanya dalam beberapa detik selama berada pada jangkauan pelayanan GSM. Lebih dari sekadar pengiriman pesan biasa, layanan SMS memberikan garansi SMS akan sampai pada tujuan meskipun perangkat yang dituju sedang tidak aktif yang dapat disebabkan karena sedang dalam kondisi mati atau berada di luar jangkauan layanan GSM. [5]

SMS adalah layanan untuk mengirim dan menerima pesan tertulis (teks) dari maupun kepada perangkat bergerak (mobile device). Pesan teks yang dimaksud tersusun dari huruf, angka, atau karakter alfanumerik. Pesan teks dikemas dalam satu paket atau frame yang berkapasitas maksimal 160 karakter. Arsitektur sistem GSM sendiri adalah seperti tergambar di bawah ini:

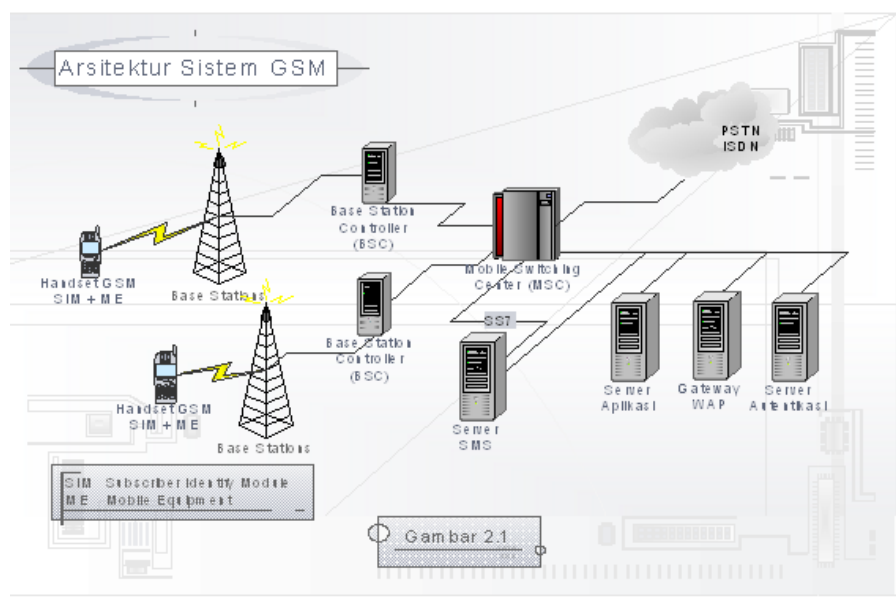

Gambar 1. Arsitektur Sistem GSM

SMS adalah data tipe asynchronous message yang pengiriman datanya dilakukan dengan mekanisme protokol store and forward. Hal ini berarti bahwa pengirim dan penerima SMS tidak perlu berada dalam status berhubungan (connected/online) satu sama lain ketika akan saling bertukar pesan SMS. Pengiriman pesan SMS secara store and forward berarti pengirim pesan SMS menuliskan pesan dan nomor telepon tujuan dan kemudian mengirimkannya (store) ke 
server SMS (SMS-Center) yang kemudian bertanggung jawab untuk mengirimkan pesan tersebut (forward) ke nomor telepon tujuan. Keuntungan mekanisme store and forward pada SMS adalah, penerima tidak perlu dalam status online ketika ada pengirim yang bermaksud mengirimkan pesan kepadanya. Karena pesan akan dikirim oleh pengirim ke SMSC yang kemudian dapat menunggu untuk meneruskan pesan tersebut ke penerima ketika ia siap dan dalam status online dilain waktu. Ketika pesan SMS telah terkirim dan diterima oleh SMSC, pengirim akan menerima pesan singkat (konfirmasi) bahwa pesan telah terkirim (message send ). Hal-hal inilah yang menjadi kelebihan SMS dan populer sebagai layanan praktis dari sistem telekomunikasi bergerak. [6]

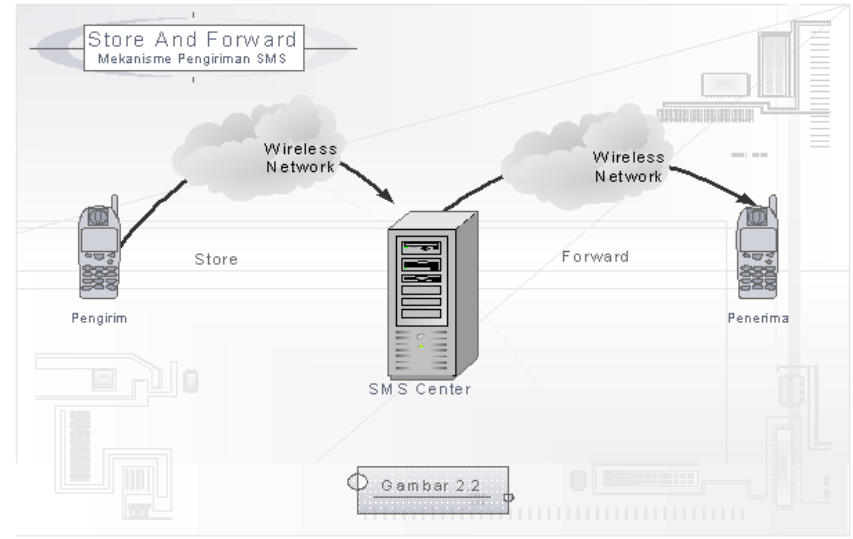

Gambar 2. Store and Forward Mekanisme Pengiriman SMS

SMS menjadi layanan messaging yang populer dan digemari oleh masyarakat. Layanan SMS dapat diintegrasikan dengan layanan GSM yang lain seperti voice, data, dan fax. Karena itu pesan SMS selain digunakan untuk pengiriman pesan person to person juga digunakan untuk notifikasi voice dan fax mail yang datang kepada klien dan kandidat. Selain itu SMS juga berharga murah, bersifat simple dan personal, serta dalam pengoperasiannya tidak terlalu mengganggu kesibukan pemakainya, karena mereka dapat mengirim atau menerima pesan pada waktu yang mereka kehendaki. [5]

\subsection{Metode Pengumpulan Data}

1) Observasi

Dalam hal ini penulis langsung melihat atau mengadakan pengamatan ke bagian-bagian yang ada hubungannya dengan sistem informasi KHS mahasiswa.

2) Wawancara

Melakukan wawancara dengan pihak yang berkaitan dengan alur permasalahan. Wawancara ini dilakukan untuk melengkapi bahan penulisan yang kurang dari pengamatan. Hal ini untuk bahan pertimbangan ke arah perbaikan dari proses yang ada.

\subsubsection{Analisa}

1) Analisa Masalah

Sering kali para pelamar kerja menunggu waktu yang lama untuk mendapatkan jadwal interview setelah pelamar tersebut dinyatakan lolos dalam spesifikasi. Hal itu sering terjadi salah satu penyebabnya adalah karena banyaknya tenaga kerja yang harus dihubungi oleh perusahaan outsourcing. Bagi para klien untuk meminta tenaga kerja bisa melalui telepon tetapi hal itu harus dilakukan berulang kali karena sibuknya bagian operator yang melayani tenaga kerja lainnya, atau melalui fax hal itu juga memerlukan proses yang lama.

2) Pemecahan Masalah

Masalah yang terjadi diatas adalah bagaimana mencari solusi untuk membantu para klien dan kandidat memperoleh tenaga kerja bagi klien sesuai dengan kriteria yang diinginkan dan juga mudah dalam mendapatkan informasi tentang ketenagakerjaan. Begitu juga dengan para kandidat yang ingin mengetahui jadwal interview apabila sudah dinyatakan lolos dalam spesifikasi.

Dengan menggunakan aplikasi ini diharapkan dapat mempermudah bagi klien maupun bagi kandidat. Bagi para klien maupun bagi para kandidat yang menggunakan aplikasi ini bisa mendapatkan beberapa fasilitas layanan yang diberikan untuk para klien dan kandidat. 


\section{Hasil dan Pembahasan}

\subsection{Rancangan Basis Data}

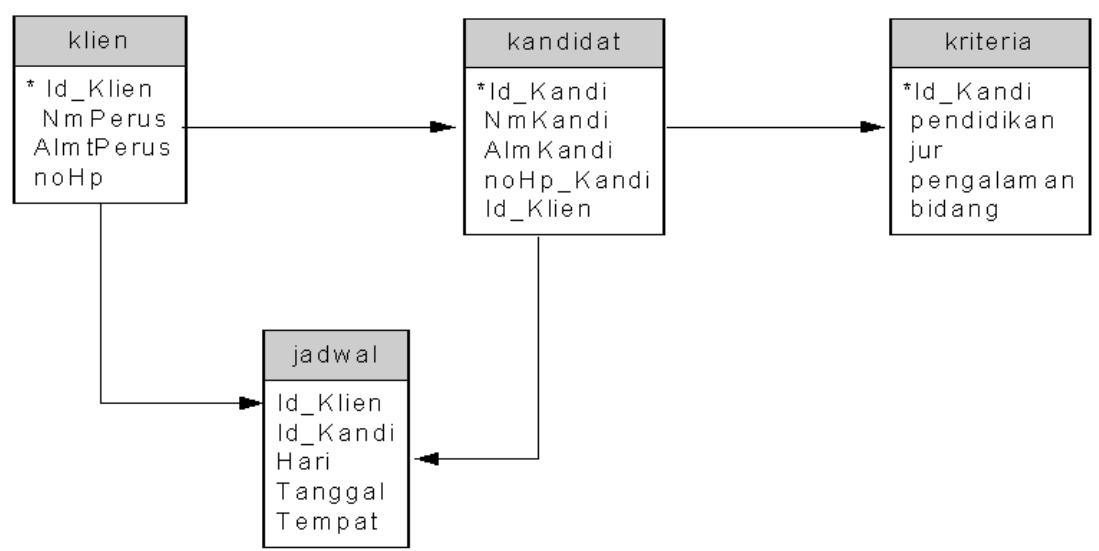

Gambar 3. Rancangan Basis Data Perekrutan Tenaga Kerja

\subsection{Tampilan Layar SMS}

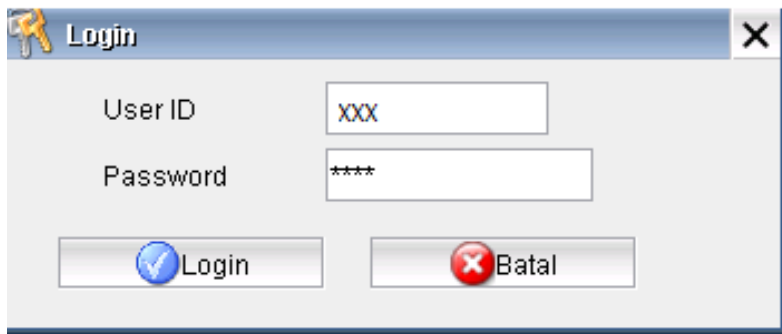

Gambar 4. Tampilan Login Admin

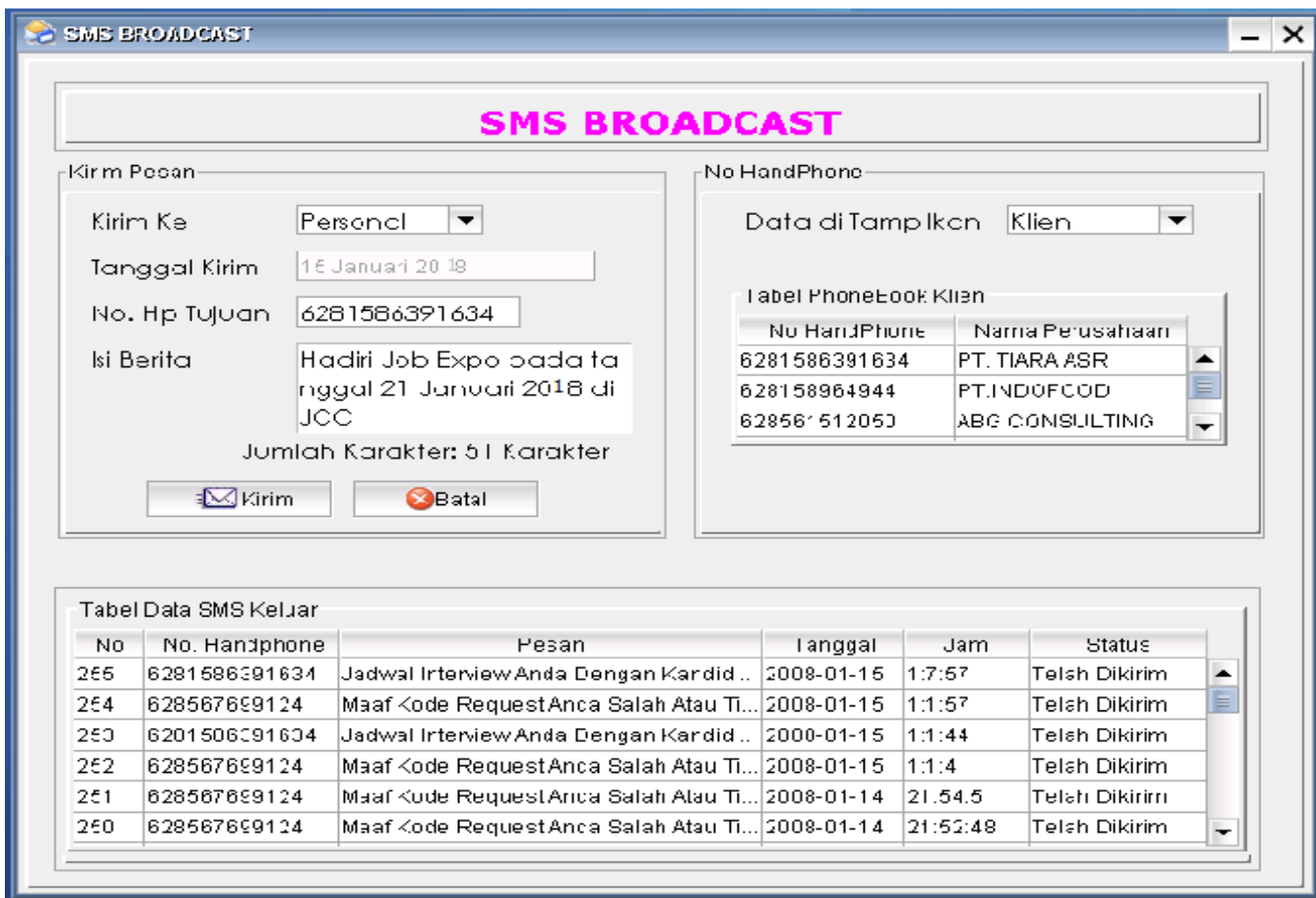

Gambar 5. Tampilan Layar SMS 
ILKOM Jurnal Ilmiah Volume 10 Nomor 3 Desember 2018

\subsection{Tampilan Data Klien}

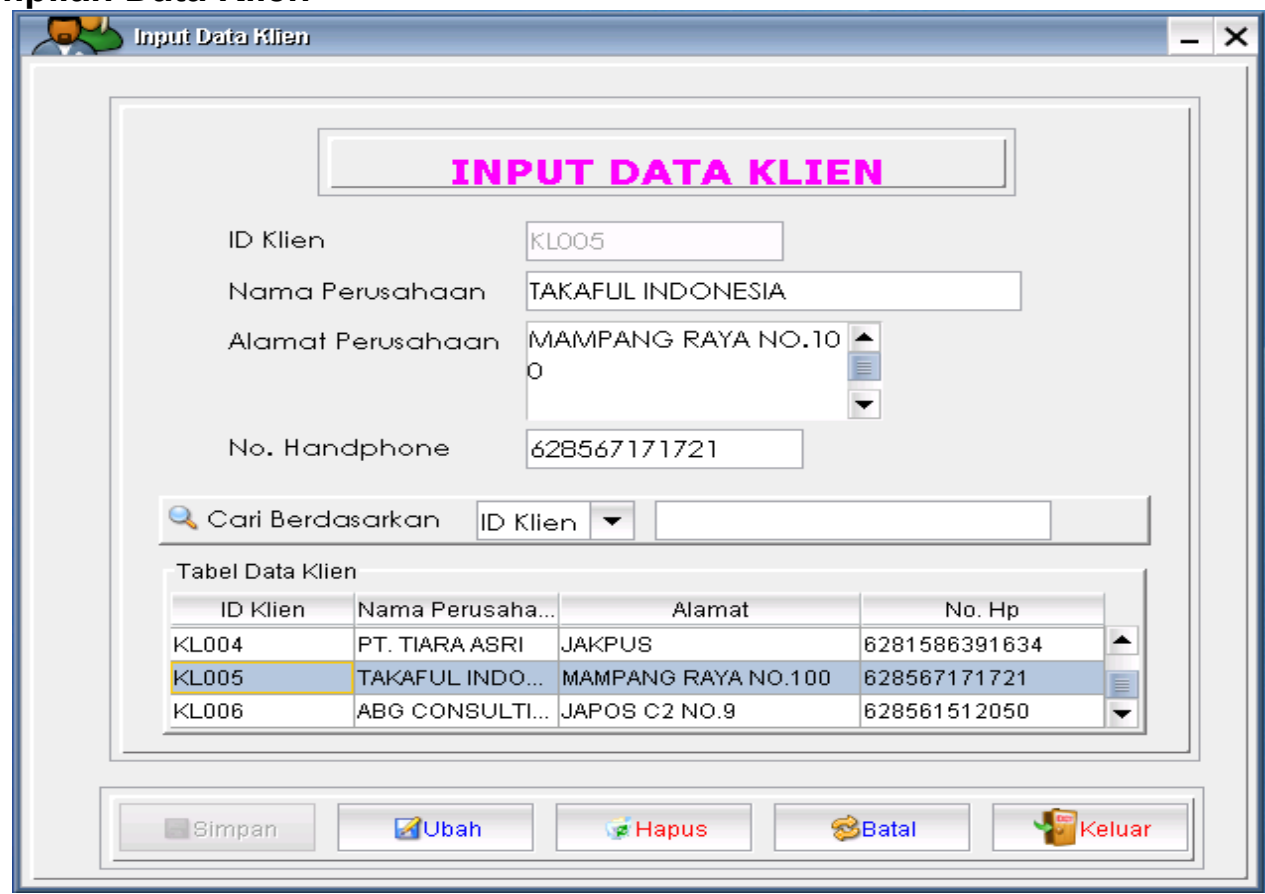

Gamabar 6. Tampilan Layar Data Klien Yang di input dan sudah Terinput

\subsection{Tampilan Data Kandidat}

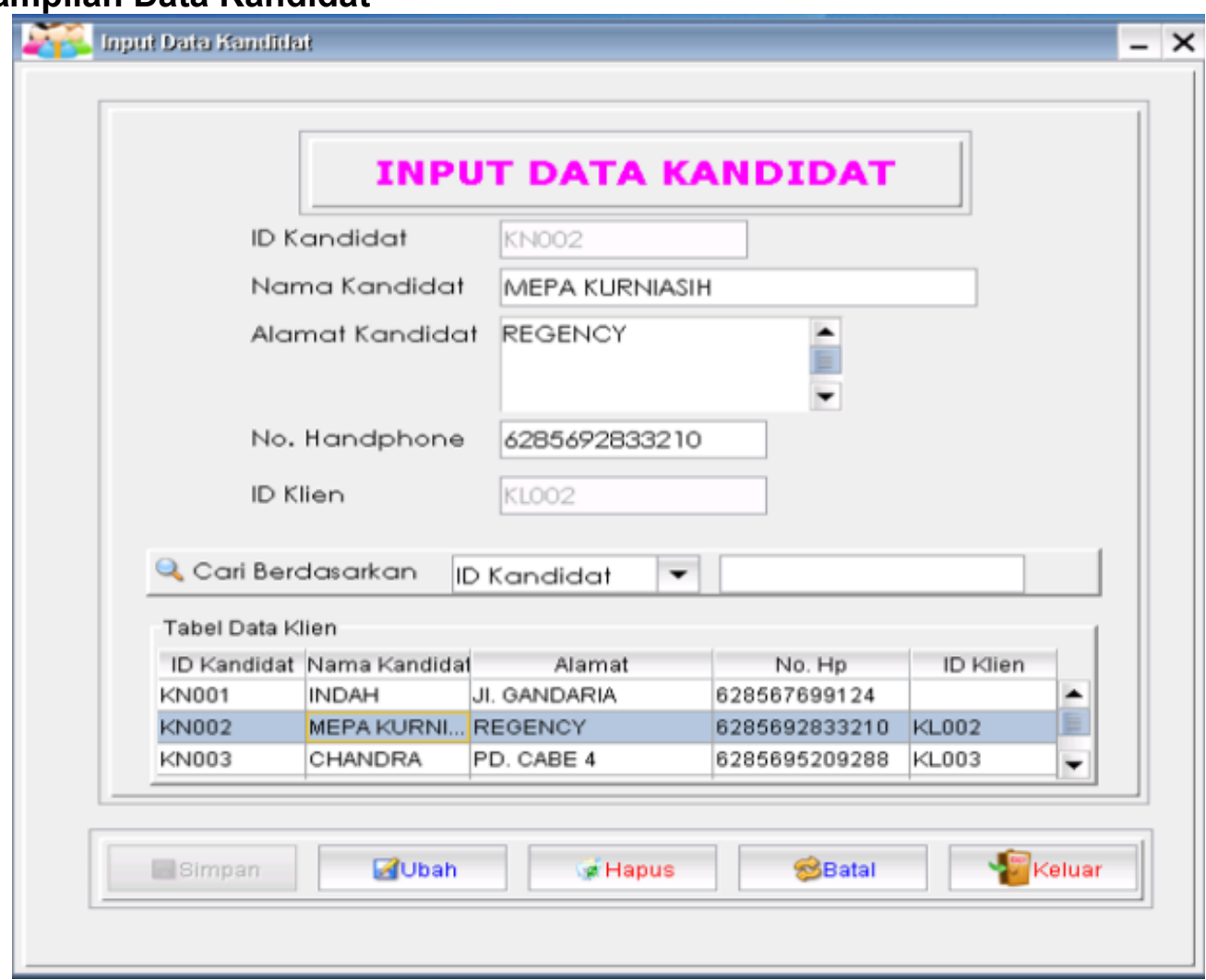

Gambar 7. Tampilan Layar Data Kandidat Yang di input dan sudah Terinput 
ILKOM Jurnal Ilmiah Volume 10 Nomor 3 Desember 2018

\subsection{Tampilan Kriteria}

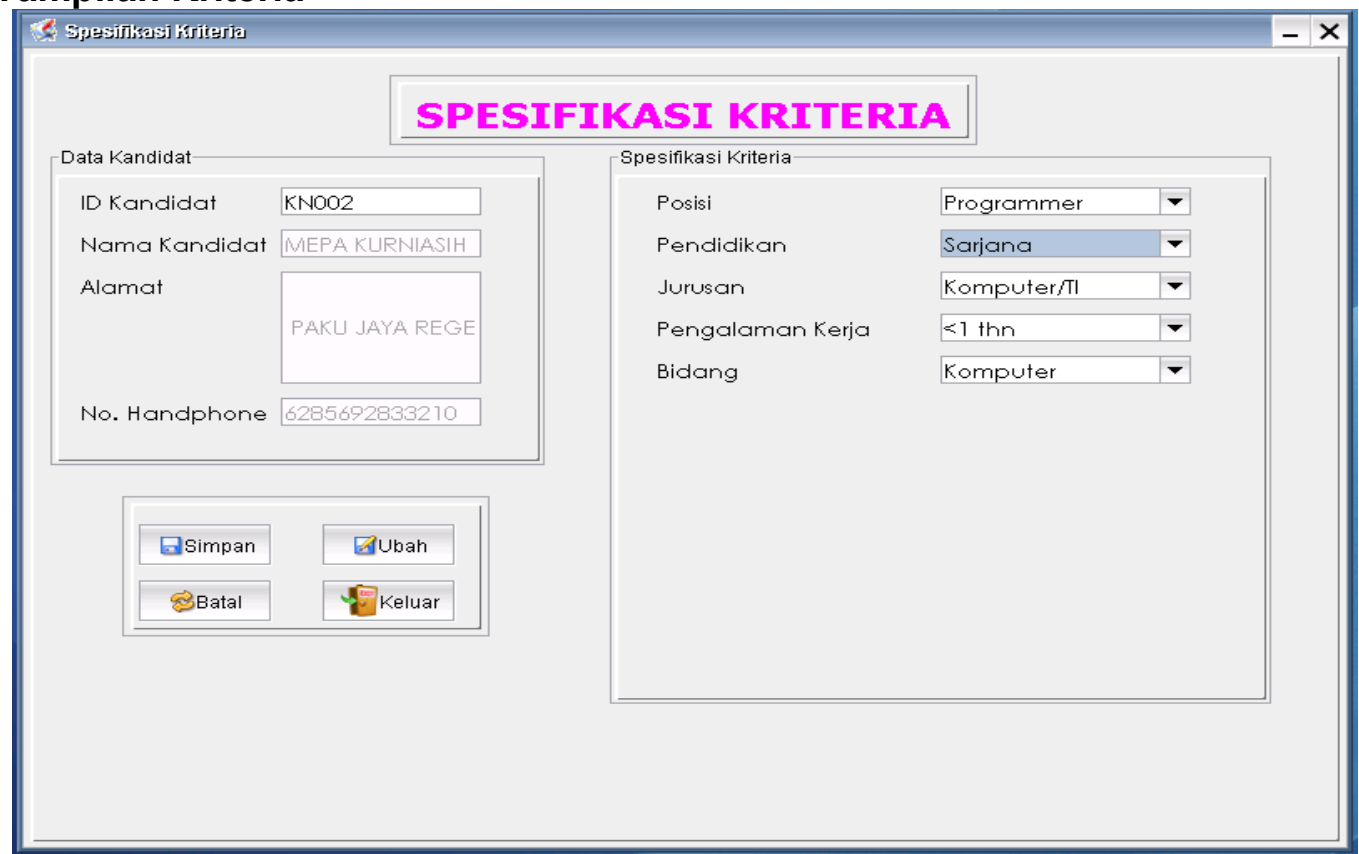

Gambar 8. Tampilan Layar Kriteria berdasarkan Sfesifikasi

\subsection{Tampilan Jadwal interview}

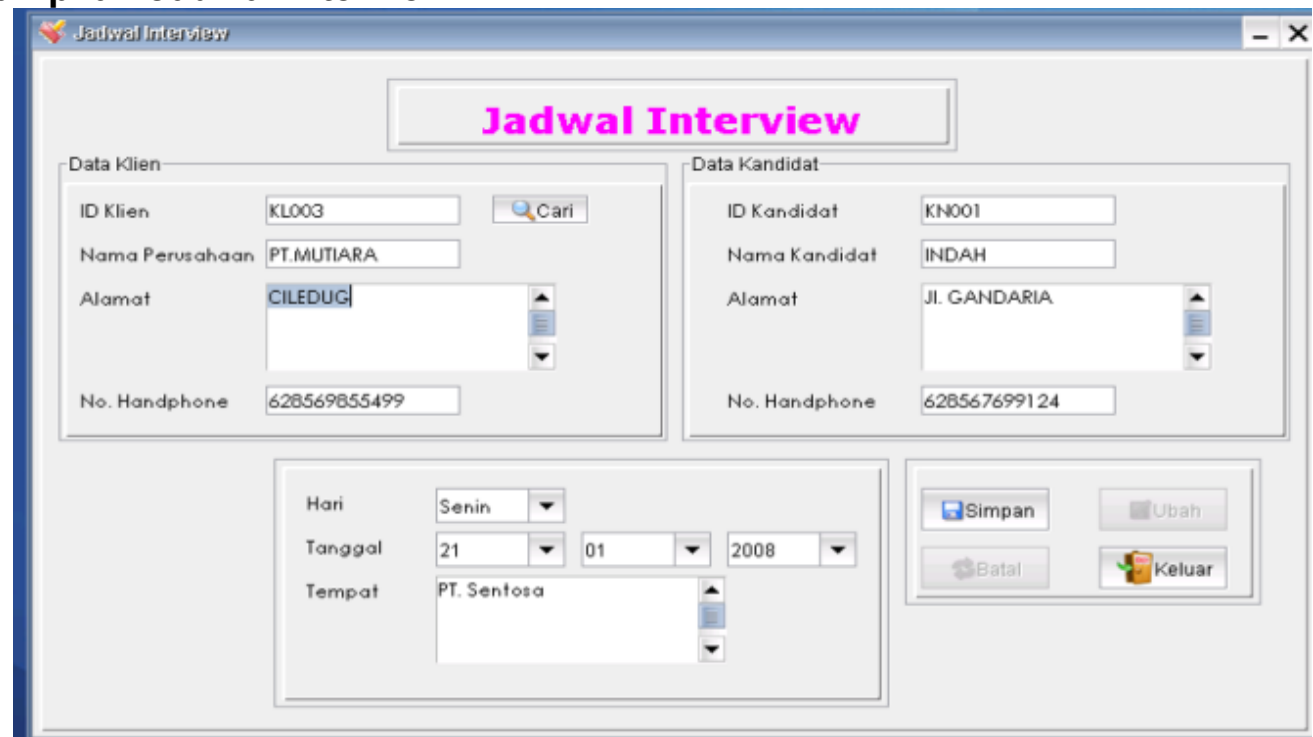

Gambar 9. Tampilan Jadwal Interview

\section{Kesimpulan dan saran}

\subsection{Kesimpulan}

Kesimpulan yang didapat dari Sistem yang berbasis SMS ini adalah dalam penggunaan Sistem Informasi yang berbasis komputer dan SMS diharapkan dapat membantu meringankan masalah yang dihadapi oleh klien dan kandidat dalam mendapatkan informasi masalah ketenagakerjaan . Sehingga dapat disimpulkan sebagai berikut :

a. Aplikasi SMS ini dibuat untuk memudahkan para klien untuk meminta tenaga kerja tanpa menunggu lama untuk menelpon. Dan para kandidat untuk mendapatkan informasi jadwal interview.

b. Dengan aplikasi ini para klien dan kandidat mendapatkan informasi tenaga kerja maupun informasi lainnya secara otomatis. 


\subsection{Saran}

Sistem aplikasi ini belum sempurna, masih banyak kekurangan yang perlu diperbaiki agar efektifitas kinerja dapat lebih ditingkatkan Agar sistem aplikasi ini tidak terjadi kerusakan maka sebaiknya perlu ada maintenance pada sistem ini, Memperbanyak fasilitas yang memberikan kemudahan dalam berinterkasi sistem ini dengan para klien dan kandidat danPermintaan tenaga kerja dengan spesifikasi yang terbatas pada layanan SMS ini.

\section{Terima Kasih}

Terima kasih disampaikan kepada Perguruan tinggi STMIK Atma Luhur yang mendanai penelitian ini.

\section{Daftar Pustaka}

[1] Sutabri, Tata, "Analisa Sistem Informasi," Yogyakarta:Penerbit, Andi, 2012.

[2] Sutabri, Tata, "Sistem Informasi Manajemen, " Yogyakarta :,Andi, 2013.

[3] Sarwindah, "Sistem Informasi Manajemen Pemesanan Buku Pada Toko Buku Nuris,"Jurnal Teknosi.,V0l.02, pp. 77- 84, 2016.

[4] Mwhitten, Jeffrey L., Lonnie d. Bently, kevinC.Dittman. "System Analysis and Design Methods.", New york:Mc.Graw-hill.,2014

[5] Jogiyanto, "Sistem Teknologi Informasi.", Yogyakarta : Andi, 2012

[6] Komputer,Wahana,"Pengembangan Aplikasi Akademik Berbasis SMS dengan Java, " Jakarta : Salemba Infotek, 2010.

[7] Leonardo, lan, "Pemrograman Database dengan Java., Jakarta :PT. Elex Media Komputindo, 2013.

[8] Ricyanto, Isak, ST, "Dasar Pemrograman Berorientasi Objek dengan Java 2 ", (JDK1.4), Yogyakarta : andi, 2009. 